\title{
Examination of Sugarcane Yield by Simulating AquaCrop to Overcome the Irrigation Deficiency
}

\author{
R. Revathy, S. Balamurali
}

\begin{abstract}
Crop simulation models are significant apparatus used for measuring crop yield response to various conditions, also designed for conceiving systems to get better agricultural administration. Sugarcane is a major C4 crop grown in canal irrigated areas of the country. It has been observed that climatic distortions particularly precipitation and greatest temperature affect crop productivity and sugar recovery. AquaCrop is a typical model used here to develop the yield of sugarcane under different situations. The development of canopy cover is mainly affected by evapotranspiration and lacking of soil water balance. So the prime objective of this research is to study the stability of soil water in the root sector by delivering more cane yields with less water. By using AquaCrop, the crop water productivity can be maintained, canopy cover gets developed and finally the crops can be saved from destruction. It is an incorporated application programming to mimic the associations between plant, water and soil. So, field administration and water system administration should be considered for producing more water productivity. Four basic segments are required in this model namely climate, crop, field and irrigation management and soil profiles to expand the water efficiency.
\end{abstract}

Keywords: AquaCrop, Crop productivity, Climatic circumstance, Water use efficiency, Soil Profile, Field and Irrigation management

\section{INTRODUCTION}

The main dispute of the agricultural sector is to deliver supplementary nourishment with usage of less amount of water. With rapid development of population, the demands on crisp water supply raise. Determining water prerequisite of sugarcane is essential for crop planting on agricultural field, scheming and examining irrigation tasks. Sugarcane is one of the significant profitable crops in India. There are 35 millions of farmers cultivating sugarcane and another 50 million rely upon work produced by the 571 sugar factories and related ventures. In Uttar Pradesh, Maharashtra and Tamil Nadu, sugarcane assumes a noteworthy part in the state economy.

In India, it was reported about $84 \%$ of the cultivated area is under the irrigation management. It is a $\mathrm{C} 4$ plant eventually grown in tropical and subtropical zones of the world. Ideal temperature for growth of sugarcane is 32-330 C [1][2]. Because of industrialization and convergence of populace, it is theorized that there is change in climate

Revised Manuscript Received on December 05, 2019

R. Revathy, Department of Computer Applications, Kalasalingam Academy of Research and Education, Krishnankoil, Tamil Nadu, India. Email: revathy.r@klu.ac.in.

S. Balamurali*, Department of Computer Applications, Kalasalingam Academy of Research and Education, Krishnankoil, Tamil Nadu, India. Email: sbmurali@rediffmail.com. parameters which is causing morphological changes in sugarcane. Hence, this research intends to discover the importance of climatic parameters on the sugarcane production. Therefore, AquaCrop model is additionally utilized here for the prediction of sugarcane growth, phenology, water management, potential and actual yields, and yield performance under atmosphere variations and transforming situations and so forth. This model can also be utilized to enhance the sugarcane growth administration to accomplish cane production and sugar recuperation.

AquaCrop is one of the peculiar simulation models, which mainly describes the plant and soil relations. The plant usually separates water and nutrients from the root sector. This model essentially considers the field and water management since it influences the interaction. The portrayed model is connected to the environment via upper boundary so as to decide the evaporative demand Evapotranspiration (ETo) as well as offers $\mathrm{CO} 2$ and energy for the growth of sugarcane. It is quite said to be a planning tool supported for irrigated as well as rainfed agriculture. It is predominantly helpful to know the sugarcane response to environmental changes and actual yields which forewarning sugarcane production and water productivity.

\section{MATERIAL AND METHODS}

\section{A. Data Description}

\section{- Climatic Parameters}

For computing growing degree days air temperature is responsible to decide the development of crop growth and phenology, maximum and minimum temperatures are mandatory. During winter, it is sufficient to create adjustments in crop transpiration. Air temperature is needed for manipulating the stress of heat as well as cold so as to affect the crop pollination. Precipitation data is essential here to renovate the soil water balance and to estimate soil water stresses which are disturbing the growth of plant. Data can be daily, 10-daily or monthly. By means of $\mathrm{CO}_{2}$ files (estimated from intergovernmental panel on climate change (IPCC)), it enables testing the crop response under climate change scenarios. From dew point temperature, air humidity is usually obtained.

Solar radiation $(R s)$ can be anticipated from difference between maximum temperature $\left(T_{\max }\right)$ and minimum temperature $\left(T_{m i n}\right)$. It involves extraterrestrial radiation $(R a)$ for the certain location and time of the year that can be calculated by the following formula

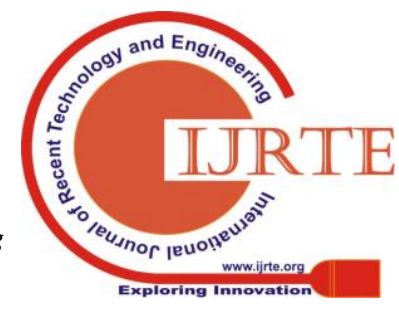




$$
R s \approx K_{R s} \sqrt{\left(T_{\max }-T_{\min }\right)} R a
$$

Wind speed is generally calculated at range of heights and further has to be transformed to 2 meter reference height. A measure of evaporative pressure of the environment is known as ETo. It also decides both crop transpiration and soil evaporation rate. To determine ETo, Aquacrop requires station characteristics like latitude, altitude and location. It can be calculated by means of built-in ETo calculator. The following parameters are used in order to import the climatic data in AquaCrop database as shown in Table I.

\section{TABLE- I: Climatic data parameters}

\begin{tabular}{|l|l|}
\hline \multicolumn{1}{|c|}{ Attributes } & \multicolumn{1}{c|}{ Measure } \\
\hline Maximum Temperature & ${ }^{\circ} \operatorname{Cor}^{\circ} \mathrm{F}$ \\
\hline Minimum Temperature & ${ }^{\circ}$ Cor $^{\circ} \mathrm{F}$ \\
\hline Relative Humidity & (max, mean, min) $\%$ \\
\hline Evapotranspiration & $\mathrm{Mm}$ \\
\hline Rainfall & $\mathrm{Mm}$ or inch \\
\hline Wind Velocity & $\mathrm{km} / \mathrm{hr}$ or $\mathrm{m} / \mathrm{sec}$ \\
\hline
\end{tabular}

Climatic database includes PLU file (rainfall data), ETo (Evapotranspiration data), TNX file (Maximum and minimum Temperature data and $\mathrm{Co}_{2}$ file $\left(\mathrm{Co}_{2}\right.$ elevation data $)$ that are finally stored and created as .cli file.

\section{- Crop parameters}

The learning objective of the AquaCrop is to know the required sugarcane crop characteristics. AquaCrop depends on a class of conservative crop parameters that are viewed in Table II. Such crop parameters do not change with period, administration practices, geographical location, typical weather and cultivators since it is a crop specific.

But non conservative parameters are the parameters, which are cultivator specific, can be influenced by crop field rule, planting node, state of the soil etc. Theses parameters need to be tuned that is calibrated to the cultivator or the environment [3].

TABLE- II: Crop parameters

\begin{tabular}{|l|l|}
\hline \multicolumn{1}{|c|}{ Parameters } & \multicolumn{1}{c|}{ Unit } \\
\hline Day 1 after transplanting & Date \\
\hline Initial canopy cover & $\%$ \\
\hline Canopy size transplanted seedling & $\mathrm{cm} 2$ / plant \\
\hline plant density & plants/ha \\
\hline Maximum Canopy Cover & $\%$ \\
\hline Root Deepening & $\mathrm{M}$ \\
\hline Harvest Index & $\%$ \\
\hline Biomass production & $\%$ \\
\hline Canopy decline in season & $\%$ \\
\hline $\mathrm{K}_{\mathrm{cTr}}$ & Unit less \\
\hline WP* & $\mathrm{g} \mathrm{m}^{-2}$ \\
\hline
\end{tabular}

The crop parameters are more needful for AquaCrop in order to acquire more efficiency. If stress in the soil fertility is considered, then the value of biomass production, average canopy decline and maximum canopy cover should be calibrated. AquaCrop model has been built to forecast the yield of sugarcane at the distinct field with requirement of limited data. In advanced simulations like field apart or farm up to the regional level, improved climatic weather record,

crop characteristics data, enhanced soil data, and some organizing practices are required [4].

\section{- Soil profile data}

AquaCrop embraces physical as well as chemical parameters of the soil profile which are shown in Table III Sampling can be conducted from $120 \mathrm{~cm}$ soil depth [3]. Usually soil profile study was allowed to demonstrate the soil characteristics at experimental field and determined the analysis of physicochemical belongings [5]. In this model, the condition of soil water in the lower, middle and upper positions has been measured as the input of the AquaCrop model in order to predict the water use efficiency of the sugarcane [6].

\section{TABLE- III: Soil parameters}

\begin{tabular}{|l|l|}
\hline \multicolumn{1}{|c|}{ Parameters } & \multicolumn{1}{c|}{ Unit } \\
\hline Thickness & $\mathrm{M}$ \\
\hline Saturation & vol \% \\
\hline $\mathrm{FC}$ & vol \% \\
\hline Water Productivity & vol \% \\
\hline $\mathrm{K}_{\text {sat (saturation) }}$ & $\mathrm{mm} /$ day \\
\hline Penetrability & $\%$ \\
\hline Gravel & $\%$ \\
\hline Organic matter & $\%$ \\
\hline
\end{tabular}

AquaCrop updates the soil water balance by maintaining the path of the inward and outward water changes over the limitations. Soil gets nourished with water either through rainwater ( $\mathrm{R}$ ) or irrigation process (IR). Element of $\mathrm{R}$ often set off which is meant to be surfaced runoff (SRO). A little depth of ground water table is connected to under root of the splant via capillary rise (CR). Evaporation of soil (E), crop transpiration ( $\mathrm{Tr}$ ), and also deep percolation losses (DPL) are the processes that extract water from the all the water bodies. In this model, soil water balance is estimated by

$$
\mathrm{W}_{\mathrm{r}, \mathrm{t}+1}=\mathrm{W}_{\mathrm{r}, \mathrm{t}}+(\mathrm{R}-\mathrm{SRO})+\mathrm{IR}+\mathrm{CR}-\mathrm{E}-\mathrm{Tr}-\mathrm{DP}
$$

where $\mathrm{Wr}, \mathrm{t}$ and $\mathrm{Wr}, \mathrm{t}+1$ are the water contents in the root zone $r$ at time $t$ and $t+1$ respectively. DPL occurs once after extreme rainfall or excessive irrigation.

\section{B. Process of AquaCrop}

AquaCrop model simulates sugarcane yield within four steps that makes the modeling approach clear as shown in Fig. 1 [7].

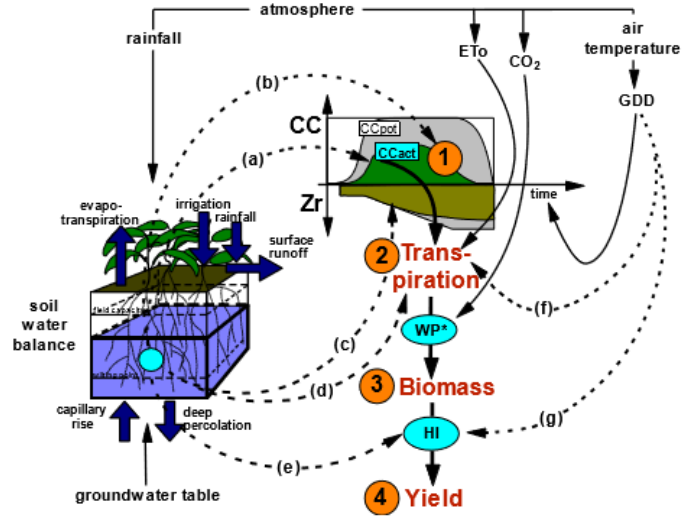

Fig. 1. Computation process of AquaCrop by 4 Steps process 
Water Productivity (WP) and growth of sugarcane are mainly considered by means of the radiation seized by the crop canopy. Hence, an accurate model is required for canopy development for predicting the growth of sugarcane and WP. Three varieties of cane canopy development grown in different seasons and localities were estimated by the method of interrupting photosynthetically active radiation [8]. AquaCrop model simulates $\mathrm{CC}$ by means of a method on leaf level as well as expansion of the leaf which is calculated from maximum temperature and unbalanced water productivity. Foliage growth is articulated only by $\mathrm{CC}$ not by leaf area index. Therefore, $\mathrm{CC}$ is expressed as

$$
\mathrm{CC}=\frac{\text { Green canopy covering uppermost layer of soil }}{\text { Total uppermost layer of soil surface }}
$$

AquaCrop model derives crop transpiration and evaporation with excellent performance for sugarcane. Transpiration was generally lower when compared to evaporation because of leisurely growth of sugarcane. That's why accumulated crop transpiration was elevated by providing appropriate irrigation for enhancing the crop yield. This model attained high performance in ETo simulations and it was actually simulated by $1330 \mathrm{~mm}$ in sugarcane plant [4]. The crop coefficient is proportional to $\mathrm{CC}$ and therefore differs all over life course of the sugarcane plant and makes a connection with CC simulation. The canopy development as well as stomata closure is affected when the demand of water is greater than the amount of water available and this directly enables the affliction of crop transpiration.

In Aquacrop, water productivity (WP) is used to estimate biomass collected each day by using sugarcane WP parameter that is normalized for ETo. Consequently, the ratio of ground biomass then turns to harvestable yield which has been evaluated using harvest index $(\mathrm{HI})$ parameter that rises over the growing season and reacts to stress of water as well as temperature [7]. This model formed above ground tree biomass (B) which is comparative to high quantity of crop transpiration. In AquaCrop, WP has normalized for the effect of the climatic conditions which is valid for various sites, seasons, and $\mathrm{CO} 2$ absorptions.

AquaCrop urges the sugarcane yield response to water over a growing season [7]. The above ground tree biomass (B) that incorporates the entire photosynthetic foodstuffs of sugarcane throughout the year. The crop yield is finally obtained from B with the help of its portion called HI parameter. The concrete $\mathrm{HI}$ has acquired by fine-tuning for water stress while simulating the AquaCrop model. This model clearly understands the consequence of weed attack, top soil lushness, salinity of soil, canopy development stress, ground biomass production and crop transpiration.

It is also a supporting tool for irrigation strategy. Water productivity is more essential in this model to increase the sugarcane yield. There is a difference between biomass water productivity (BWP) and evapotranspiration water productivity (WPET) in AquaCrop. WPET is sometimes referred to as water use efficiency (WUE) [9]. The WP refers to the amount of biomass that can be obtained with a certain quantity of water which is expressed in $\mathrm{kg}$ (biomass) per $\mathrm{m} 3$ of water transpired which is stated as follows.

$$
\mathrm{WP}=\frac{\text { biomass produced expressed as } \mathrm{Kg} \text { (biomass) }}{\text { water transpired expressed as } \mathrm{m}^{3}(\mathrm{Tr})}
$$

Similar to what happens in deficit irrigation, the soil water contains high salt concentration which extracts various plant responses. Two main things have been explained, first one happened by decreasing in soil water potential due to the osmotic effects, and next due to the toxicity of definite ions like sodium.

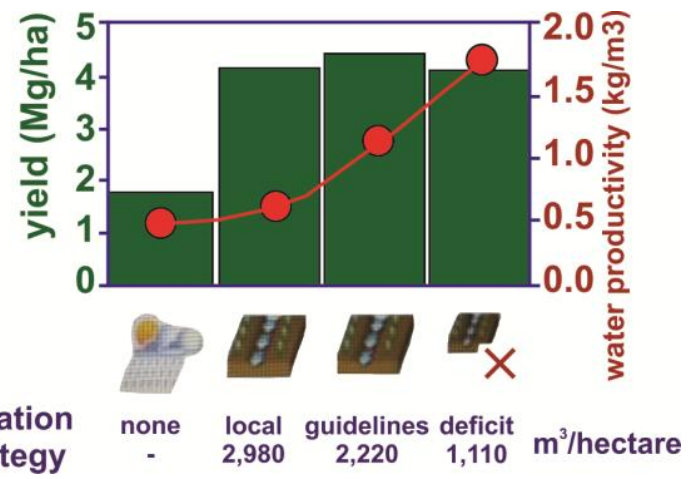

Fig. 2. Sugarcane yield (bars) and ET water productivity (line)

Usually, the shortage of irrigation permits the farmer to improve the sugarcane yield [10]. The sugarcane productivity is slightly lower during full irrigation, but during deficit irrigation there is a high-rise in productivity with maximized evapotranspiration water productivity (WPET). The chart in Fig. 2 evidently illustrates that the yield of sugarcane increases due to complete irrigation and also insists that deficit irrigation increases WPET.

\section{RESULT AND DISCUSSION}

In order to find the growing degree days (GDD) for deciding the cane developmental growth and also for moulding any alteration in biomass production throughout winter, data regarding climatic conditions are required by AquaCrop for each simulation pertaining to a day [4]. This model parameterization includes cultivar, non-conservative, and conservative parameters resulting from the calibration of AquaCrop for the preferred leafy crop [11]. Certainly, extreme climatic changes in the last 10 years enable the attentive responses to canopy growth during crop simulation. The tests done by [11] illustrated that AquaCrop inclined to overvalue the biomass production responding to elevated $\mathrm{CO} 2$ when compared with other models. This model suggests that the crop dependency is based on certain environmental scenario and the availability of water at the lowest part of the plant. The CC growth and ETo are affected as a result of the stress in water balance [12]. The soil water depletion threshold value is calibrated in order to control the effect of water stress on leaf development and ETo [13]. A magnificent conflict can be seen between the observed and the simulated $\mathrm{CC}$ of fine watered treatment and fair irrigation treatment while calibration. At rest, CC of plants from the rainfed approach was under predictable by the model all over the growing season [14].

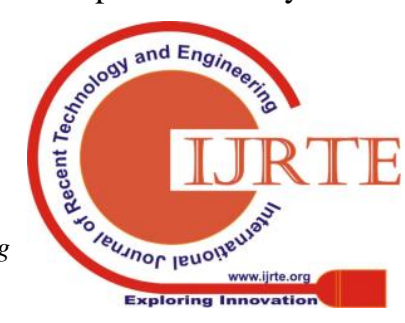


AquaCrop is calibrated with cane yield, biomass, WP and crop water use that make the model prediction efficient which could be validated by statistical methods like coefficient of determination (R2), root mean squared error (RMSE), index of agreement (d), mean absolute percent error (MAPE) and model efficiency (ME) [15][16].

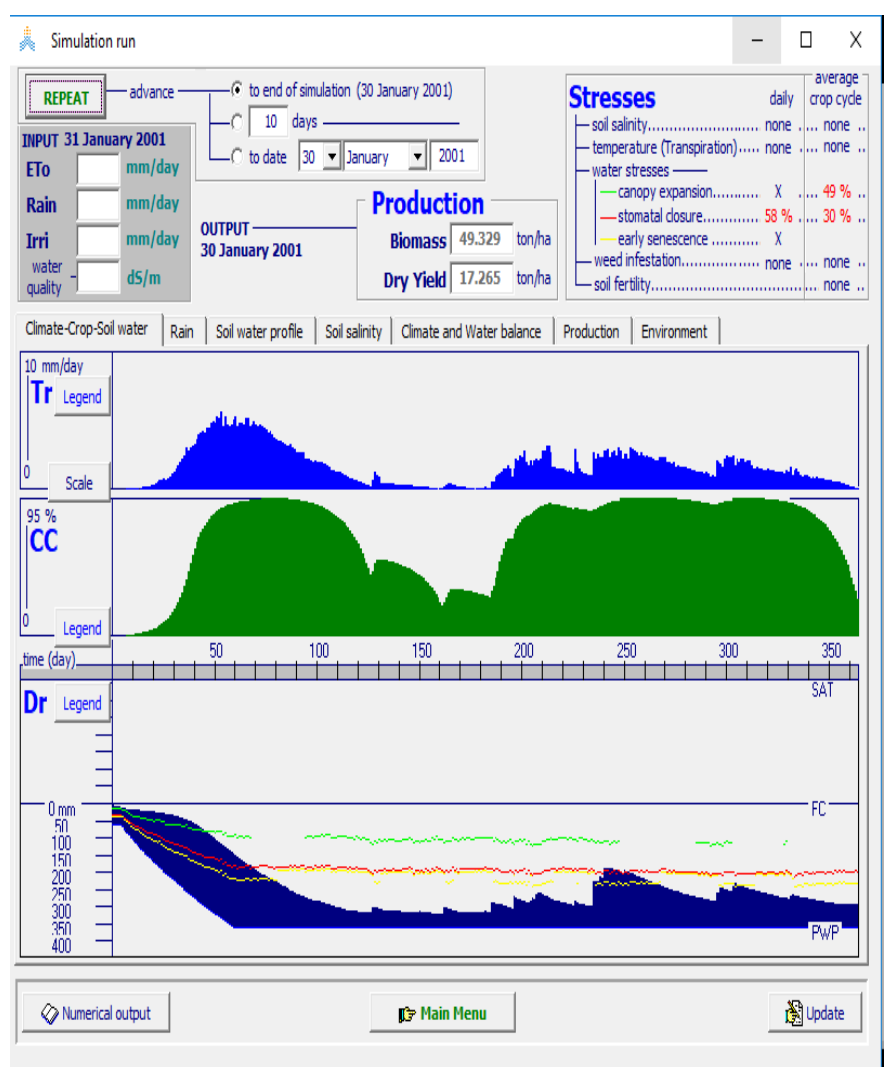

Fig. 3. Graphical output of climate-crop-soil water in the simulation run menu

In Fig. 3, Dr refers to soil water depletion of the root zone, $\mathrm{CC}$ refers to the development of green canopy cover, and $\mathrm{Tr}$ refers to transpiration which are plotted accordingly as in simulation. In the first 80 days, extreme rainfall raised the water content then the soil moisture in the root zone is at field capacity. Thus transpiration process and CC expansion matched and improved as parallel. The lack of rain during the time period 120-190 leads to make fall in root zone water content. Hence, it reaches lower to the threshold affecting the development of canopy cover and distress the crop transpiration. Due to full irrigation, soil moisture is within available water capacity throughout the crop period progressively. Therefore, the transpiration matched with full irrigation schedule all over the development of CC. Continuous amendments of production of biomass and crop yield are displayed for each simulation run. This model proves to be powerful tool in order to design optimum irrigation schemes. Simulation results are finally recorded in output files and can be recovered in excel sheet for processing and analysis [17][18].

AquaCrop model achieved improved accuracy in terms of error measures, crop growth development and utilization of water as compared with APSIM-Sugarcane, QCANE, CANEGRO models. It can efficiently analyze the impact of climatic fluctuations on sugarcane production and support in developing the adaption approaches to minimize the vulnerability of sugarcane production according to the climate change.

\section{CONCLUSION}

AquaCrop model could sufficiently simulate canopy cover by means of matching with evapotranspiration and soil water depletion under irrigation excluding with few challenges under rainfed circumstance. Although it is a tool for both irrigated and rainfed agriculture, it improves the efficiency in water use under irrigation strategy. Running simulation with AquaCrop model is proficient instead of conducting field experiments since AquaCrop uses relatively small number of parameters. It balances simplicity so that it requires only commonly available input. This model obtains good accuracy and robustness which is based upon plant physiological and soil water planning process. This model confirmed that it could be used as a decision taking tool by enhancing the WP in sugarcane cultivations under various scenarios.

\section{ACKNOWLEDGMENT}

The first author would like to thank the management of Kalasalingam Academy of Research and Education for providing fellowship to carry out the research work.

\section{REFERENCES}

1. Wahid, A., "Physiological implications of metabolite biosynthesis for net assimilation and heat-stress tolerance of sugarcane (Saccharum officinarum) sprouts", Journal of Plant Research, Vol.120 (2), 2007, pp.219-228.

2. Singh, K.K., Mall, R.K., Singh, R.S. and Srivastava, A.K., "Evaluation of CANEGRO sugarcane model in East Uttar Pradesh, India", Journal of Agrometeorology, Vol. 12(2), 2010, pp.181-186.

3. Vanuytrecht, Eline, Dirk Raes, Pasquale Steduto, Theodore C. Hsiao, Elias Fereres, Lee K. Heng, Marga Garcia Vila, and Patricia Mejias Moreno, "AquaCrop: FAO's crop water productivity and yield response model", Environmental Modelling \& Software, Vol. 62, 2014, pp. 351-360.

4. Smith, M, "Irrigation scheduling and water distribution", In Conference Internationale: les besoins en eau des cultures, Paris (France), 1985, pp. 11-14.

5. Pawar, G.S., Kale, M.U. and Lokhande, J.N., "Response of AquaCrop model to different irrigation schedules for irrigated cabbage", Agricultural Research, Vol. 6 (1), 2017, pp. 73-81.

6. Bahmani, O., and Eghbalian, S, "Simulating the response of sugarcane production to water deficit irrigation using the AquaCrop model", Agricultural Research, Vol. 7 (2), 2018, pp. 158-166.

7. Foster, T., Brozović, N., Butler, A.P., Neale, C.M.U., Raes, D., Steduto, P., Fereres, E. and Hsiao, T.C., "AquaCrop-OS: An open source version of FAO's crop water productivity model”, Agricultural water management, Vol. 181, 2017, pp.18-22.

8. Singels, A., \& Donaldson, R. A, “A simple model of unstressed sugarcane canopy development", Congress of the South African Sugar Technologists Association (SAUS), Vol. 74, 2000, pp. 151-154.

9. Smith, M, "CROPWAT: A computer program for irrigation planning and management", Food and Agriculture Organisation, Vol. 46, 1992, pp. 1-123.

10. Largani, A. S., "Modelling regional land use: the quest for the appropriate method", PhD thesis, Wageningen University, Wageningen, 2013, pp. $1-149$.

11. Bello, Z. A., and Walker, S., "Evaluating AquaCrop model for simulating production of amaranthus (Amaranthus cruentus) a leafy vegetable, under irrigation and rainfed conditions", Agricultural and Forest Meteorology, Vol. 247, 2017, pp. 300-310 
12. Nyathi, M. K., van Halsema, G. E., Annandale, J. G., and Struik, P. C., "Calibration and validation of the AquaCrop model for repeatedly harvested leafy vegetables grown under different irrigation regimes", Agricultural Water Management, Vol. 208, 2018, pp. 107-119.

13. Raes, D., Steduto, P., Hsiao, T. C., and Fereres, E, "AquaCrop - the FAO crop model to simulate yield response to water: II. Main algorithms and software description", Agronomy Journal, Vol. 101 (3), 2009, pp. 438-447.

14. Raja, W., Kanth, R. H., and Singh, P, "Validating the AquaCrop model for maize under different sowing dates", Water Policy, Vol. 20(4), 2018, pp. 826-840.

15. Abdul-Ganiyu, S., Kyei-Baffour, N., Agyare, W. A., and Dogbe, W., "Evaluating the effect of irrigation on paddy rice yield by applying the AquaCrop model in Northern Ghana", In Strategies for Building Resilience against Climate and Ecosystem Changes in Sub-Saharan Africa, Springer, Singapore, 2018, pp. 93-116.

16. De Carvalho, A.L., De Souza, J.L., Almeida, A.C.D.S., Lyra, G.B., Lyra, G.B., Teodoro, I., Ricardo Araújo Ferreira Junior, I., Magalhães, D. and Santos, L.R., "Sugarcane productivity simulation under different planting times by DSSAT/CANEGRO model in Alagoas, Brazil", Emirates Journal of Food and Agriculture, 2018, Vol. 30 (3), pp.190-19.

17. Vanuytrecht, E., Raes, D., Willems, P., and Geerts, S, "Quantifying field-scale effects of elevated carbon dioxide concentration on crops", Climate Research, Vol. 54 (1), 2012, pp. 35-47.

18. Farahani, H. J., Izzi, G., and Oweis, T. Y., "Parameterization and evaluation of the AquaCrop model for full and deficit irrigated cotton", Agronomy journal, Vol. 101 (3), 2009, pp. 469-476.

\section{AUTHORS PROFILE}

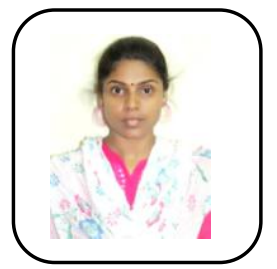

R. Revathy received B. Sc, M. Sc and M. Phil in computer science from Madurai Kamarajar University, Tamil Nadu. She is pursuing Ph.d in the department of computer applications at Kalsaslingam Academy of Research and Education, Krishnankoil, Tamil Nadu since 2017. Her current research interests include data mining and machine learning algorithms.

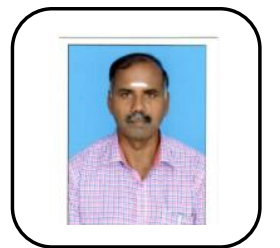

S. Balamurali is a Professor of Statistics and Director of ComputerApplications at the Kalasalingam Academy of Research and Education. He received his undergraduate, postgraduate and doctoral degrees in Statistics from Bharathiar University, India. His research interests include applied statistics, data mining, network security and bioinformatics. 